\title{
MODEL WRITTEN TEXTS IN THE RECOMMENDED SENIOR HIGH SCHOOL ENGLISH TEXTBOOKS
}

\author{
Dwi Rukmini \\ Semarang State University, Indonesia
}

\begin{abstract}
This article is based on the study on the model written texts provided in the Senior High School English textbooks. It is aimed at finding out whether those models are written by considering the English two contexts, cultural and situational, which encircle them. The data are all written texts provided in the six recommended English textbooks published by six different publishers. The results reveal that only eleven out of 115 model written texts tend to be incompatible with the two contexts encircling them, this implies that 104 of them $(93.43 \%)$ are likely to be compatible and can be used as model texts.
\end{abstract}

Key words: genre, rhetorical development, lexicogrammartical feature, model text

Accessing through the internet seems to be a part of human's life in this era. Doing it people can communicate, obtain information, get entertainment, etc. However since English is the world language, when using the internet, they will be posed to English written texts. This tends to be problem for those who are not good English users like many Indonesians. In Indonesia, the ones having low English proficiency are not only common people but the educated ones as well. This is supported by one of the Indonesian state rectors who stated that 'the reason why the greatest numbers of university members fail to get a scholarship to study abroad is their lack English proficiency' ('Kompas' newspaper, 2006:31). One of the efforts done to improve the condition was that the government of Indonesia through the department of education and culture changed the English curriculum used at schools in 2004 to the competence based curriculum. (CBC) 
Since then , the English education has changed its focus from sentences in isolation to a text. The change also coincides with the suggestion given by Kern (2000:19). He states that the recent language education should focus on connected stretches of language (text) which are realized as communicative acts. The implication is that students should be involved in working with text (spoken and written). They do not only discuss about the content of a text as it was done when implementing previous English curriculum, but also how the text is constructed through its elements, and how those elements arevrealized through lexicogrammatical choices.

That a text should be the basis of learning a language is also supported by Carrell whose research results reveal that in English second language learning, learners who possessed and activated the appropriate text background knowledge when processing texts were found to retrieve more information (Carrell, 1985:464).

Since a text is the concrete form of discourse (Murcia, et al., 2000:5), the focusing of the language education on text can be regarded as one of the efforts to suit the latest communicative competence model offered by Murcia, et al. (1995); the one that CBC is philosophically based on which proposes language learners to achieve the discourse competence. According to them, the discourse competence is comprised of linguistic competence, socio-cultural competence, actional competence, and supported by the strategic competence. The linguistic competence is not only related to grammar, but lexis, phonology in addition to morphology and syntax, too; the sociocultural competence is used to achieve appropriateness; the actional competence is to convey and understand communicative intent; and the strategic competence is used when communication breakdown takes place in the actual communication. In order to achieve the discourse competence language learners should achieve all those comprising competencies.

CBC is then developed and in 2006 schools in Indonesia - elementary, junior, and senior high, started to use the school based curriculum of which the fundamental principles are exactly the same with the ones of CBC. The difference is only on the designing of syllabus; every school has been given a chance to design its syllabus based on its characteristics and facilities.

In the process of teaching, like in other countries, teachers of English in Indonesia also make use of English textbooks which are usually written based on the current curriculum. Considering the central role of a text in language learning, this study, on which this article is based, concerns with the model 
texts provided in the text book particularly on whether they can be model texts for learning. However, the study only analyzes six recommended textbooks provided for senior high school (SHS). The recommendation was actually given to 14 publishers on December 12, 2006 after their textbooks had been reviewed by professional evaluators coordinated by 'Pusat Perbukuan'-- an institution which is responsible of the quality of educational textbooks in Indonesia. This implies that the recommendation is reasonable.

\section{THEORY OF COMMUNICATION}

The communication theory underlying this study is the one suggested by Fiske (1990) who proposes two schools of communication, process school and semiotic school. The study be-longs to the latter. The diagram below illustrates how meanings of a writer in form of a text are interpreted by the reader. When the meanings of a reading text are read by someone, the messages in the forms of signs and codes interact with the reader producing meanings created by the text writer (producer). In doing so s/he brings with her/him the aspects of her/his cultural experience which have relation to the codes signs that make up the text.

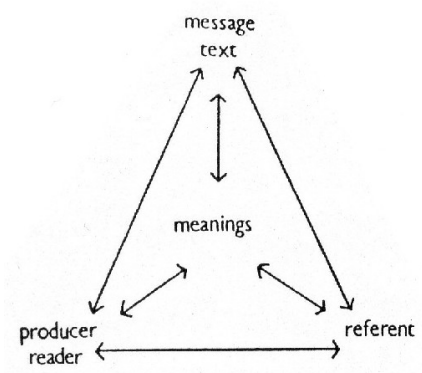

Message and Meaning (adopted from Fiske, 1990:4)

Since the cultures of Indonesian and English are different, Indonesian students need to have English cultural experience which they can use when reading English texts. Considering it, they should get experience not only in understanding the content of the text but also analyzing the generic structure (GS) - 
common elements that construct a given text, and the realization of elements through the lexicogrammar used; even more so, when they write an English text.

\section{GENERIC STUCTURE OF A TEXT}

'A text is a collection of meanings appropriate to its contexts' (Butt, 1995:11). The contexts of a text, according to Derewianka (as cited in Hammond, et all.1992:2) in his model of language, consist of two - the cultural context and the situational one. The correlation between text and those two contexts is illustrated well on the diagram below.

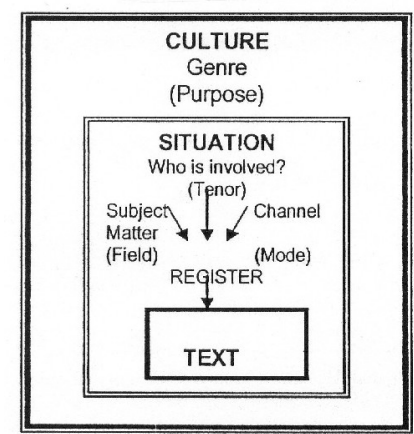

Derewianka's language model (adopted from Hammond, et al., 1992:1)

Referring to the diagram, the context of culture gives rise to genre. The term genre used to be related to the category of literary compositions, such as novels, plays, short stories, etc. However, today, it is widely used in rhetoric, literary and linguistics to refer to the distinctive type of text (Chandler in htttp://www.aber.ac.uk/media/Document/intgenre2.html, 1997:1). The various kinds of text are characterized by the different elements the text is structured. The structure of elements tends to help the achievement of the text's the social purpose. Description's social purpose, for example, is to describe a particular person, place or thing therefore it has two elements: identification descriptions. Procedure's social purpose is to describe how something is accomplished 
through a sequence of actions or steps and therefore it has three elements: goal (list of things needed) steps.

The elements of a text can be obligatory and optional. It is obligatory if the existence in the text is compulsory. Unlike the optional element, a text may have it or not. The list of things needed, the second element of Procedure in the example above, is optional and in this study it is coded with brackets; not all Procedures need this element; for example procedure of posting a letter, dividing an angle, welcoming a guest in a hotel, etc.

The context of situation influences the realization-- the lexicogrammatical features used to construct a text in order to achieve its social purpose. Because of its context of situation, Description, for example, usually has the following lexicogrammatical features: focus on specific participants, use of attributive and identifying processes, frequent use of ephitets and classifiers in nominal groups, and the use of simple present tense. Procedure's lexicogrammatical features tend to focus on generalized human agents, use of simple present tense , often imperative, use mainly of temporal conjunctions (or numbering to indicate sequence) and use mainly of material processes. Both the structure of the text and its realization are conventions suggested by the parents' community (Swales,1990). If the text is in English, the parents' community is English.

\section{MODEL TEXT}

An English model text is a text which fulfills both the elements and lexico-grammatical features required by English community. Ideally, the texts in the textbooks are model texts the students work with. As it is explained above, when working with a text, students do not only learn the content of the text but also its generic structure and lexicogrammatical features, since based on the current curriculum, at the end of the course they should be able to write various kinds of texts. The provision of model text is inevitable, otherwise students do not have appropriate learning experiences which they need when they create a text both spoken and written.

\section{METHOD}

The study is aimed at finding the quality of the written model texts available in the textbooks for SHS students, explaining their respective generic 
structures and linguistic features, whether they serve to accomplish their social purposes.

With regard to the scope, this study is included in discourse analysis since it analyses text as a whole. It also analyses the realization of generic structure, i.e. the choices of lexicogrammar used to realize the generic structure therefore it is included in stylistics particularly linguistics. The data are reading texts in the textbooks, so they are included in non literary text analysis in education.

It has been mentioned in the abstract that the data of this study are taken from 6 textbooks which are published by different recommended publishers. To cover the textbooks used for every grade, the textbooks are chosen purposively, two of them are for the tenth grade, two for the eleventh, and the other two are for the twelfth grade. All the reading texts (reading passages) in the chosen textbooks are the data of the study, they are all 115 reading texts.

The analyses are done twice, the first is the generic structure analysis and the second is its realization analysis.

\section{Generic Structure Analysis}

Every text has its own generic structure. Considering this, every text under study is segmented into elements, followed by the labeling of each element and its function. Those are done to find out the genre of the text, such as the one shown below:

\section{Spring Gardens Apartment}

\begin{tabular}{cll}
\hline Element & \multicolumn{1}{c}{ Function } & \multicolumn{1}{c}{ Text } \\
\hline Identification & $\begin{array}{l}\text { Identifying what is going } \\
\text { to be described, in this } \\
\text { case is the Spring Garden } \\
\text { Apartment. }\end{array}$ & $\begin{array}{l}\text { The } \\
\text { Apartment Complex offers } \\
\text { you and your family coun- } \\
\text { try living at its best. }\end{array}$ \\
\hline Description 1 & $\begin{array}{l}\text { Describing the surround- } \\
\text { ing and location. }\end{array}$ & $\begin{array}{l}\text { Surrounded by beautiful } \\
\text { woods and hills, Spring } \\
\text { Garden is located ten miles } \\
\text { outside the city but is only } \\
\text { minutes downtown on the } \\
\text { freeway. }\end{array}$ \\
\hline Description 2 & $\begin{array}{l}\text { Describing the inside of } \\
\text { the apartment; what each }\end{array}$ & $\begin{array}{l}\text { Unfurnished two bedroom } \\
\text { apartments are available. }\end{array}$ \\
\hline & & \\
\hline
\end{tabular}




\begin{tabular}{lll}
\hline & $\begin{array}{l}\text { apartment has and the pos- } \\
\text { sibility to take pets inside } \\
\text { it. }\end{array}$ & $\begin{array}{l}\text { Each apartment has a } \\
\text { dishwasher, central heat- } \\
\text { ing, air conditioning, and } \\
\text { laundry room. Children } \\
\text { pets are welcome. }\end{array}$ \\
\hline Description 3 & $\begin{array}{l}\text { Describing the existence } \\
\text { of sports facilities and }\end{array}$ & $\begin{array}{l}\text { In addition, there are tennis } \\
\text { and basketball courts, two } \\
\text { parking area. }\end{array}$ \\
& $\begin{array}{l}\text { swimming pools, and a } \\
\text { playground. There are two } \\
\text { parking spaces for each } \\
\text { apartment. }\end{array}$ \\
\hline
\end{tabular}

The above text is included in Description since the required elements of Description, identification and description, are provided in it.

\section{Generic Structure Realization Analysis}

The generic structure realization of a text is, done by analyzing every clause in the text in terms of its three meanings a clause can encode which are suggested by Halliday (1994) :interpersonal, textual and ideational.

Eggins (1994:146) suggests that analyzing the interpersonal meaning means esta-blishing a relationship between the semantic organization of interaction and grammatical differences in the Mood configurations in clauses of different Mood types, and see the role of modality in interaction. Mood is the subject and finite of the clause while the rest of the clause is called the Residue. The textual meaning analysis concerns a clause character as a message. What is mainly analyzed here is the thematic structure of a clause. Theme is the first meaning which is put at the beginning or in the front part of a clause. How the Themes of clauses in the text are structured govern how well the messages are developed in the text.

The ideational meaning analysis views a clause as its function to express experience; that is the clause as representation. 'There are three semantic categories which explain in a general way how phenomena of the real world are presented as linguistic structure -- circumstance, process, and participant' (Gerot, et al. 1994:52). Analyzing ideational meaning means exploring who does what to whom; who/what is what/who, when, where, why or how function. 
The example below shows how the three meaning analyses are done to a given clause.

\begin{tabular}{l|c|c|} 
A rule is & "no talking while eating". \\
\hline \multicolumn{2}{|c|}{ Mood } & Residue \\
\hline Subj & Fin & Complement \\
\hline Th & \multicolumn{2}{c|}{ Rheme } \\
\hline Token & Rel P & Value \\
\hline
\end{tabular}

The first and second rows are the interpersonal meaning analyses. 'A rule is' is the Mood, and 'no talking while eating' is the Residue. The Mood indicates that the clause is declarative, it gives information. In addition, the Finite of a clause may change its function. If $i s$ in the above clause is changed to should the clause is suggestive.

The third row is the textual meaning analysis. The Theme is ' $A$ rule'; the writer intends to first expose ' $A$ rule' as the point of departure of the meaning, and it becomes the most important meaning exposed to the reader. By designing the Themes well a writer can maintain the meanings being conveyed cohesively.

The fourth row is the ideational meaning analysis. In the above example, it tells what is what, 'The rule' is 'no talking while eating'. 'is' therefore is classified as identifying Relational Process. 'no talking while eating' is the value of the token 'A rule'.

The results of the analyses are then compared to the lexicogrammatical features conventions suggested by the parents' community. Those conventions are used as the parameters of the study. An example of convention of lexicogramatical features which are usually used in Narration are: focus on specific and usually individualized participants, use of materials, behavioural, verbal, relational, and mental processes, use of temporal con-junctions and temporal circumstances, use of past tense.

\section{FINDINGS AND DISCUSSION}

The presentation of findings is divided into two, the findings related to the text generis structure, and the one related to the realization. 


\section{Findings related to the text rhetorical development}

The table below shows the result of the text rhetorical development analysis. There are 14 genres provided in 6 analyzed textbooks. The required genres, according to SBC, are 13. The one which is not required but available in the textbooks is anecdote. That genre used to be required when the competence based curriculum was launched in 2003.

\begin{tabular}{|c|c|c|c|}
\hline No & Genre & Text number & Percentage \\
\hline 1. & Procedure & 33,34 & $1.7 \%$ \\
\hline 2. & Spoof/recount & $36,49,59,71,77,97$ & $5.2 \%$ \\
\hline 3. & Report & $\begin{array}{l}4,20,37,38,39,40,41,42,43,44 \\
45,55,66,72,99,108,113\end{array}$ & $14.8 \%$ \\
\hline 4. & News item & $8,23,47,48,52,63,74,98$ & $7 \%$ \\
\hline 5. & Description & $\begin{array}{l}7,13,18,22,24,56,57,60,67,82, \\
86\end{array}$ & $9.6 \%$ \\
\hline 6. & Anecdote & $35,50,61,62,78,79,110$ & $6.1 \%$ \\
\hline 7. & $\begin{array}{l}\text { Analytical exposi- } \\
\text { tion }\end{array}$ & $1,2,3,17,21,28,53,65,76,92$ & $8.7 \%$ \\
\hline 8. & $\begin{array}{l}\text { Hortatory exposi- } \\
\text { tion }\end{array}$ & $5,9,64,70,80,81,95$ & $6.1 \%$ \\
\hline 9. & Narrative & $\begin{array}{l}11,14,19,25,26,27,29,30,31 \\
68,69,75,85,87,90,91,96,101 \\
105,106,109,111,114\end{array}$ & $20 \%$ \\
\hline 10. & Explanation & $6,10,12,46,83,88,107$ & $6.1 \%$ \\
\hline 11. & Discussion & $15,16,54,58,73$ & $4.3 \%$ \\
\hline 12. & Review & $89,93,94,100,102,103,112$ & $6.1 \%$ \\
\hline 13. & Commentary & $32,104,115$ & $2.6 \%$ \\
\hline 14. & Others & 51,84 & $1.7 \%$ \\
\hline
\end{tabular}

The Table of Findings Related to the Generic Structure

However the SBC does not include anecdote as the required genre to learn for SHS students since it is culturally biased. Things which are funny for English people may not be funny for Indonesian. This finding also implies that the textbook writers do not keep up with the latest issue of the curriculum. Usually improvements and revisions of curriculum tend to be done continuously. 
In the table above, the term 'Others' in the last row of the second column is used to refer to reading texts which have uncommon generic structure, and therefore cannot be classified into any genre. There are two texts which cannot be classified into any genre.

The proportion balance between genres does not tend to be achieved. Procedure constitutes the smallest contribution, $1.74 \%$ of all 115 reading texts available in 6 ana-lyzed textbooks. Both of them are recipes. Actually there are many other procedural texts which are posed to people of this era; tools, devices, appliances, various kinds of electronics sold in the market are usually accompanied with English manuals. They can actually be used as models of Procedures of which the content can provide life skills for the learners.

Narration gives $20 \%$ contribution, this seems to be crucial domination. After checking the curriculum it is found that this very genre is always included as required genre to learn in every grade of SHS; this means within three years of education students are involved with this very genre. This implies that the stating of genres for every term does not seem to consider the contribution balance of all genres. Compared to other genres Narration does not tend to support SHS students'academic knowledge so much. Some of the portion of narration can be given to other genres which are needed for academic communication, such as making commentary, reviews, procedures (of observations, researches). Fourteen out of 23 Narrations are imaginative stories. This brings about an indication that only a small number of textbook writers know that Narrations are not always imaginative stories. They can also be factual, like for example; Situ Gintung dissaster, an accident of an aeroplane, the resign of Soeharto, etc. Those can be more challenging compared to imaginative narrations.

Two reading texts have problem in terms of their elements and are not likely to be appropriate as model texts. The problem is caused by the textbook writer's suggestion on the genre to those texts. The suggestion is proved inappropriate. The writer claims that one of them is Discussion, however the text has only one point of view. Discussion should at least consist of two arguments, argument for and argument against. This indicates that the text has no differing argument, so it can not be classified as Discussion. The other text is also suggested by the writer to be included as Discussion, but the result proves that the text should have been included in News Item since all elements are the ones belonging to News Item. 


\section{Findings related to the text generic structure realization}

Nine reading texts have problems with their generic structure realization therefore they do not tend to be used as model texts. The inappropriate realizations are as follows:

There are clauses in 3 reading texts which have no subjects. This can not happen in written texts. One of them is written: Behind the diaphragm is a small cup filled with carbon. This clause only has a finite and no Subject. Actually the placing of an adjunct at the beginning of a clause followed by a relational process is acceptable as long as it is not a written text. Since it is so, there should have been inserted between diaphragm and is. There in that clause has no representational function but it is required because of the need of a Subject in English.

One reading text has a minor clause which functions as a major clause, it is written: Next, the pilot. This is an inappropriate use of a minor clause; all clauses in a written text should be major clauses, unless if it is direct speech. Observing further, it is found that one of the writers is a native speaker of English, this finding also suggests that a native writer cannot be guaranteed as being always correct in creating a text. The issue that a native is always able to provide good model text does not tend to be always true.

The time circumstance in one of the Recounts is inappropriately used, it is written: A few minutes ago, it started raining hard, and now the shower was coming down. Recount's social purpose is to retell past event, and now should have been changed to then. The clause should have been also rephrased to: and then it slowed down.

One of the analyzed Descriptions has this clause: You must visit Soho, the city's current arts scene center. The finite must has an implication that the clause tends to express an absolute persuasion and should not have been used in Description. That finite can not be used to describe Soho. One of the alternatives is by changing the finite should to is and the clause becomes: Soho is the center of current arts.

Three reading texts under study do not tend to use modals appropriately. One of them is found in one of Analytical Expositions. The problem is in the realization of the first clause. It is written: Cars should be banned in the city. The finite should (modal) involves the writer's intent to persuade the readers to accept his advice. This clause, therefore, does not reflect the fact. In Analytical Exposition the argument given should be based on the fact otherwise the text 
with that clause is classified as Hortatory Exposition which argues that something should or should not be the case. This very clause can be changed to, for example, Cars bring about problems in the city.

The explanation on the textual meaning above mentions that the Themes of the text clauses when they are organized well can maintain cohesion between clauses in the text. Two reading texts under study do not make use of the thematization organization well. One of them is found the following paragraph.

Siberian tigers come from the mammal family.

You can find Siberian tigers in the Ammur-Ussuri region of Siberia, also

China and Korea

The repetition of the phrase Siberian tigers could have actually been avoided if the thematization organization is good. For instance, by using a zig-zag strategy, and the paragraph is changed to Siberian tigers come from the mammal family. These mammals can be found in the Ammur-Ussuri region of Siberia, also China and Korea.

The omission of you in the text is done to make students of SHS aware that scientific writing should be content neutral, a writer should not include the reader in the text's content.

\section{CONCLUSION AND SUGGESTION}

The model written texts of the analyzed textbooks are likely to be compatible with SBC. There is only one genre, Anecdote, which is not required by that curriculum, available in one of the textbooks under study. Most of the analyzed reading texts tend to have appropriate generic structure and $90.44 \%$ of them have appropriate generic structure realization, and therefore most of them tend to achieve their respective social purposes. However, the inappropriate generic structure and its realization must be improved since being model texts, they should have had appropriate both generic structure and realization; considering that both of them, in the process providing experience to the students, are discussed thoroughly to form their appropriate text background knowledge.

\section{REFERENCES}

Butt, D, et al. 1995. Using Functional Grammar--An Explorer's Guide. Macquarie: National Center for English Language Teaching and Research Macquarie University. 
Candler, _ D. _ 1997. _ An Introduction to Genre Theory. 'http:/www.aber.ac.uk/media/Document/intgenre/intgrnre2.htmb. (19 December, 2006)

Carrell, P. L. 1985. Facilitating ESL Reading by Teaching Text Structure. TESOL Quarterly.

Eggins, S. 1994. An Introduction to Systemic Functional Linguistics. London: Pinter Publisher.

Fiske, J. 1990.Introduction to Communication Studies. New York: Routledge.

Gerot, L. and Peter W. 1994. Making Sense of Functional Grammar. Sydney: Gerd Stabler.

Hammond, J. 1992. English for Social Purposes. Sydney: National Centre for English Language Teaching Research Macquary University.

Halliday, M.A.K. 1994. An Introduction to Functional Grammar.London: Edward Arnold.

K-6 English Syllabus and Support Document. 1994. Sydney: Board of Studies NSW.

Kern, R. 2000. Literacy and Language Teaching. Oxford: Oxford University Press.

Kurikulum Bahasa Inggris Sekolah Menengah Atas dan Madrasah Aliyah2004', 2003. Jakarta: Departemen Pendidikan Nasional.

'Keluar Negeri...'. 2006. Article on 'Kompas' Newspaper. January, 24 ${ }^{\text {th }}$, page 53.

Lee, D. Y.W. 2001. Genres ,Register, Text Types, Domains, and styles:Clarifying the Comcept and Navigating a Paththrough the BNC Jungle- Language Learning and Technology. Volume 5, Number 3, September 2001: 37-72. Lancaster. 'ihttp:ilt.edu/vol5num3/lee//i (December 19, 2006).

Murcia, M. C, Zoltan D., \& Sarah T. 1995. Communicative Competence: A Paedagogically Moti-vated Model with Content Specifications. Issues in Applied Linguistics, Vol.6 No.2. pp. 5-35 
Murcia, M. C., Elite O. 2000. Discourse and Context in Language Teaching- A guide for Language Teachers. Cambridge: Cambridge University Press.

"Pengumuman tentang Buku Teks Pelajaran yang Memenuhi Kelayakan untuk Digunakan dalam Pembelajaran untuk SMP dan MTs, serta SMA dan MA”. 'Kompas' Newspaper, 12 th January, 2006.

Roth, M.; Desiree. 1999. Text and Genre Literacy in the Classroom. Belo Horizonte, MG:UFMG e ABRAPUI. pp. 94-02.

Swales, J. M. 1990. Genre Analysis. Cambridge:Cambridge University Press. 